\title{
Mother's Health-seeking Behaviour and Childhood Mortality in Pakistan
}

\author{
GHULAM MUSTAFA ZAHID
}

\begin{abstract}
The paper examines the Mother's Health-seeking Behaviour and Childhood Mortality in Pakistan. This is based on the 1990-91 Pakistan Demographic and Health Survey (PDHS), a nationally representative survey covering all four provinces of the country. It was found that neonatal, infant, and child mortality rate is the highest among children of mothers aged less than 20 years. Infant and Child mortality rate is likewise higher among first and higher order births than among births of second or third order. It has further found that mortality declines as the length of the birth interval increases. The results reveal that the education of mother has significant effect on the neonatal, infant and child survival, as mother's education increases the chances of survival of neonatal, infant and child also increases. Health care factors such as antenatal care, place of delivery, assistance at delivery and immunisation also influenced neonatal, infant and child mortality. The paper suggests that for the improvement of the health conditions of children in Pakistan, first, it is necessary that the educational status of the population in general, and of mothers in particular, should be improved, and second, the health services should be accessible and available for the promotion of health care practices.
\end{abstract}

Parents in all societies raise their children in a way that is generally compatible with the demands of their physical environment, socio-economic conditions, demographic characteristics, and the belief system that has been ingrained in their society. Variation in patterns of child rearing is associated with diversity in parent's control over these four dimensions of their environment. This suggests a dynamic interaction in which many factors contribute to the pattern of child care. Women are known and considered all over the world as the first providers of health care in the home. Mother's behaviour in seeking health either as a preventive or curative treatment is an important factor in determining child survivorship through the child's health and nutritional status, as well as through her own health. Women are expected by policy makers and society in general to implement the child survival revolution by:

- bringing children to be immunised four times during the first year of life;

- procuring or producing oral rehydration solutions and administering them

Ghulam Mustafa Zahid is Research Demographer at the Pakistan Institute of Development Economics, Islamabad.

Author's Note: I gratefully acknowledge the valuable guidance and helpful comments of Dr Naushin Mahmood, Chief of Research (Demography) at the Pakistan Institute of Development Economics, Islamabad. Any errors in the paper are of course my responsibility. 
to a sick child many times over the course of each day of every bout of diarrhoea;

- breast-feeding their babies on demand until the child is six months to two years old and processing and feeding proper weaning foods in frequent meals to small children at the appropriate ages;

- bringing children under age five to a weight surveillance programme monthly.

Health-seeking behaviour also includes consulting a physician during the prenatal (for mother's immunisation against tetanus), natal (place of delivery and help at delivery) and postnatal (immunisation of the child) period, especially when disease symptoms are apparent. Education of mother and father and their work status have strong effect on child survival in developing countries [Caldwell (1979) and Caldwell et al. (1983)]. The current place of residence of the parents is also an important factor in explaining differentials in child mortality patterns [Hobcraft et al. (1984)].

Mortality studies in developing countries are often related to the level of economic development of the nations, or have examined mortality differentials by socio-demographic and environmental factors, both at aggregate and individual levels within a nation [Martin et al. (1983)]. Study on infant mortality in Pakistan have been extremely limited primarily due to lack of vital registration data necessary for the estimation of levels, trends and differentials in mortality. A review of literature on mortality suggests that a gap exists in the knowledge of the factors, particularly operating at the household level, that are influential in determining mortality of children. There is, therefore, a need for a study to understand the health-seeking behaviour of mothers in affecting infant and child mortality. The study has the following main objectives:

1. to examine the pattern of health-seeking behaviour of mothers and its effects on childhood mortality;

2. to examine and compare the effects of socio-economic factors through demographic and health-seeking behaviour on childhood mortality;

3. to find out the relationship between health-seeking behaviour and childhood morality after controlling for demographic and socio-economic factors.

\section{SOURCE OF DATA AND METHOD OF ANALYSIS}

Data derives all its variables under study from the Pakistan Demographic and Health Survey(PDHS) of 1990-91, a nationally representative survey covering all four provinces of the country. The sample covered 8019 households, of which 6611 ever-married women aged 15-49 were successfully interviewed in the survey. A detailed information on women's socio-economic background, birth histories and 
health status measures was obtained [NIPS (1992)]. For the present analysis, a subset of these data, where live-births are taken as the unit of analysis, was created by extracting information from the mother's birth history and her personal bio-social characteristics as well as her health related behaviour.

As the unit of analysis, children born from one to fifteen years preceding the survey were selected as the study population, because these were the children who had experienced at least one year of exposure to the risk of dying at the time of the Survey.

Direct estimates of the probabilities of infant and child mortality were calculated for each category of independent variables. To, explore the possible relationships between the dependent and explanatory variables; bivariate analysis has been carried out. Logistic regression has then used to analyse the net effect of each of the explanatory variables on infant and child mortality. A dichotomous dependent variable, child's survival status through a specific age range, has been given a value of 1.00 if the child failed to survive through specified age, and zero otherwise.

\section{RESULTS}

\section{(a) Bivariate Analysis}

The estimates of neonatal, ${ }^{1}$ infant $^{2}$ and childhood $^{3}$ mortality of various categories of socio-economic and demographic variables are presented in Table 1.

\section{Maternal Education}

As expected, educated mothers are far more likely to use the health services, feed their children better, contracept and act in various ways to improve on traditional means of health care. The key issue is not the increased social standing of the educated women but the changes in their behaviour and attitudes [Caldwell (1979)]. The results in Table 1 confirm the hypothesis that the higher the education of mother, the lower the infant and child mortality. Evidence of an inverse relationship between level of education achieved by mother and the mortality experience of the child is also observed in several other studies in Pakistan [Sathar (1985); Alam and Cleland (1988) and Afzal et al. (1988)], indicating that the risk of death of a child decreases as the education of the mother increases. The results in Table 1 show that infant mortality rate of children born to uneducated mothers is almost double than that to children born to educated mothers e.g. is 89 per 1000 live births for

\footnotetext{
${ }^{1}$ The Multilingual Demographic Dictionary defines the neonatal mortality as 'the mortality of live born children who die before reaching a certain age, taken as four weeks or a month' [UN (1958)].

${ }^{2}$ The infant or post-neonatal mortality refers to 'deaths of children dying after neonatal period, but before reaching the age of one year' [UN (1958)].

${ }^{3}$ The childhood mortality regards to 'deaths of children dying after infant period, but before reaching the age of five years' [UN (1958)].
} 
Table 1

Distribution of Births and Probability of Dying (per Thousand) in Infancy and Childhood by Selected Characteristics, Pakistan, 1975-90

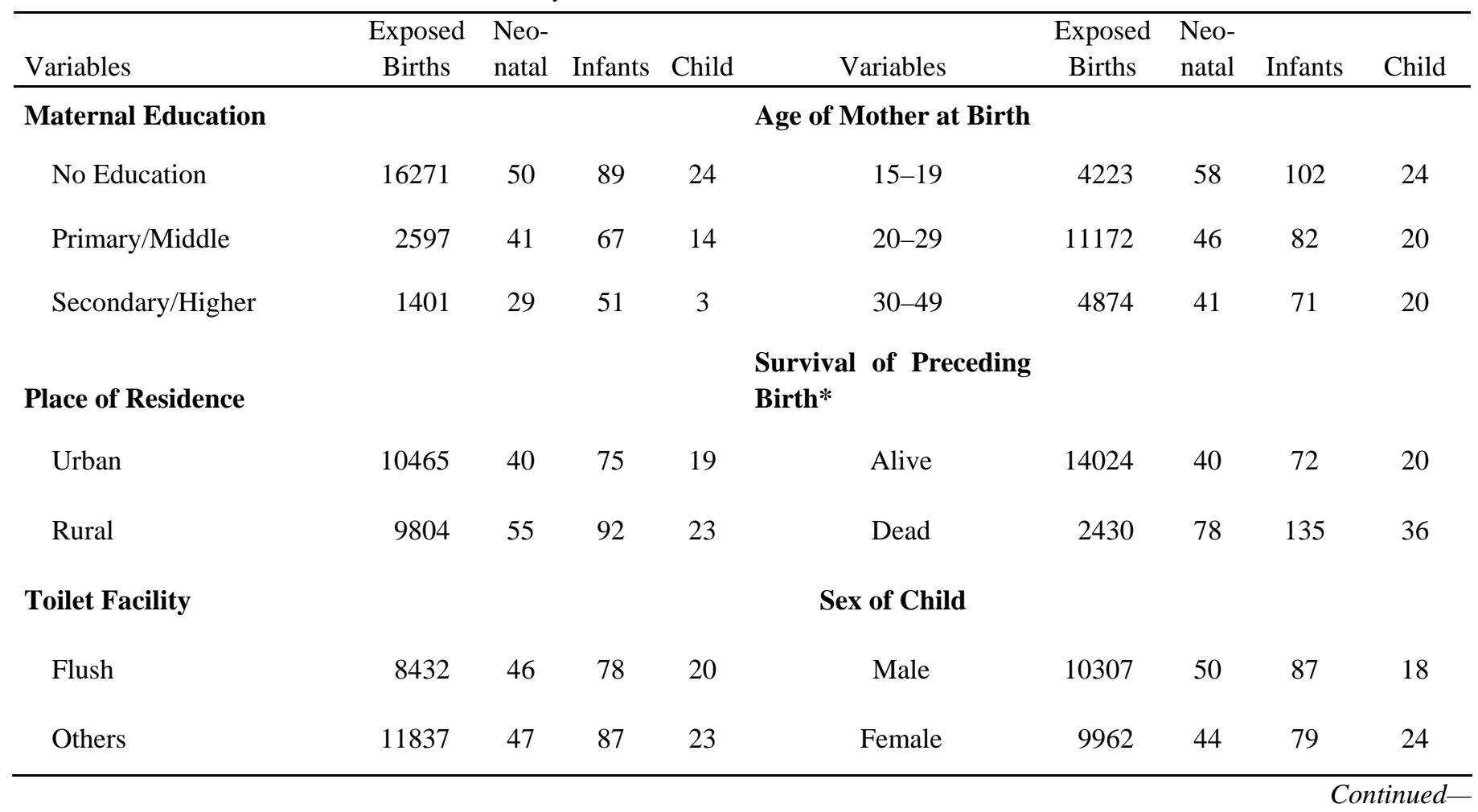


Table 1-(Continued)

\begin{tabular}{|c|c|c|c|c|c|c|c|c|}
\hline \multicolumn{5}{|c|}{ Source of Drinking Water } & \multicolumn{4}{|l|}{ Immunisation } \\
\hline Piped/Public Tap & 10840 & 47 & 79 & 19 & No & 5344 & 103 & 25 \\
\hline Spring/Well & 9155 & 48 & 88 & 22 & Incomplete & 8864 & 78 & 20 \\
\hline Others & 274 & 77 & 109 & 26 & Complete & 6061 & 72 & 17 \\
\hline Antenatal Care & \multicolumn{8}{|c|}{ BCG } \\
\hline Doctor/LHV/Nurse & 9945 & 42 & 72 & 17 & No & 14676 & 87 & 25 \\
\hline Traditional & 10324 & 53 & 93 & 24 & Yes & 5593 & 70 & 16 \\
\hline Breastfed & \multicolumn{8}{|c|}{ Polio Vaccine } \\
\hline Yes & 13875 & 46 & 80 & 20 & No & 14920 & 87 & 25 \\
\hline No & 6394 & 51 & 86 & 22 & Yes & 5349 & 70 & 15 \\
\hline \multicolumn{9}{|c|}{ Measles } \\
\hline & & & & & No & 15936 & 90 & 24 \\
\hline & & & & & Yes & 4333 & 64 & 15 \\
\hline
\end{tabular}

Source: Primary analysis of 1990-91 PDHS data. *Excludes first birth. 
uneducated mothers, and 51 per 1000 live births for mothers who have completed or higher education. Child mortality rate also differs substantially according to maternal education. The child mortality rate among children born to uneducated mothers is 24 per 1000 live births compared to 3 per 1000 live births for the highly educated mothers. The pattern is similar for neonatal mortality.

\section{Place of Residence}

Another important factor of infant and child mortality in developing countries is the place of current residence of the parents [Alam and Cleland (1988)]. Table 1 shows that neonatal, infant and child mortality rates are lower in urban than in rural areas. The differentials by place of residence may be an artifact of differences in standard of living, access to health facilities and economic factors. The type of health care and environmental sanitation available to a woman at the time of delivery are important factors in infant and child mortality.

\section{Sex Differentials}

In Pakistan markedly higher mortality, except at the neonatal stage, was found for girls than for boys [Ahmed et al. (1991)]. Discrimination against girls in intrafamily food distribution and medical care has been the explanation for the excess female mortality [Sathar (1987)]. The results in Table 1 show that neonatal mortality is higher among males (50 per 1000 live births) than females (44 per 1000 live births) due to expected biological effects. The sex differentials in mortality remain during the infancy period, 87 per 1000 for males and 79 per 1000 for females. However, child mortality is higher among females 24 per 1000 live births than among males, 18 per 1000 live births. This result suggests that there may be some gender-related differences in child rearing practices that favour boys over girls.

\section{Place of Delivery}

The place of birth of the child seems to be associated with its survival during infancy. Survival is higher among neonates, infants and children who were born in a hospital than among those who were not born in hospital. This difference is evident in Table 1. The results indicate that having ante-natal care during pregnancy increases the child's chances of survival.

\section{Breastfeeding}

Breastfeeding is a major factor in child survival. It is nutritionally useful at least for the initial period of infancy [Khan (1991)]. It provide immunity to a

number of common communicable diseases as it is rich in anti-bodies. Breastfeeding can also contribute to child survival through extending the period of post-partum 
period and by extending intervals between births. The effects of breastfeeding on infant survival appears to be greater during the early months of life and gradually diminish. The results of the study presented in Table 1 reveal that children who are not breastfed are more likely to die than children who are breastfed.

\section{Immunisation effect}

Immunisation is another factor that contributes to the child's chances of survival. As seen from the results in Table 1, there are great differences in infant and child mortality between the infants and children who are immunised and those who are not immunised. With respect to infant mortality, those infants who are not immunised experienced a mortality level 1.4 times higher than that experienced by children who are completely immunised. A difference of similar magnitude between immunised and not immunised children was observed with respect to child mortality.

\section{Drinking Water Supply}

In relation to the source of drinking water, infant and child mortality is generally lower among children whose mothers' households use piped water than those that use water from other sources. The results in Table 1 reveal that neonatal, infant and child mortality are lower among children whose mother's households used piped water than those that use water from spring, well and other sources. It is assumed that piped water is more safe and hygienic water supply compared with water from other sources, especially water from the river.

\section{Toilet Facility}

It is shown in Table 1 that children from households with flush toilets have lower infant and child mortality than those who use non-flush facilities. However, the difference was marginal with regard to neonatal mortality, infants from households with flush toilet experienced 46 deaths per 1000 live births compared to 47 deaths per 1000 live births with other type of latrine. This similar neonatal mortality risk can be explained by the fact that during infancy (neonatal) the infant is mostly breastfed and is therefore less affected by environmental factors.

\section{Age of Mother at Birth}

The results in Table 1 show that neonatal and infant mortality rate is the highest among the children born to women aged 15-19 at the birth of their children and declines thereafter with increasing age of women. With respect to child mortality, the risk of mortality to children born to mothers aged 20-29 and 30-49 are the same. 


\section{Birth Order of Child}

The relationship between birth order and infant and child mortality risk generally forms a U-shape cure. This pattern of mortality may be related to age of mother, because most first births occur to young women aged less than 20 years, and teenage mothers are biologically and mentally bear higher risks of child deaths. By contrast, higher birth order children are more likely to be born to older mother's who are physically worn out and these children face competition from older siblings for food and other resources [Rutstein (1984)]. The results in Table 1 support this contention and indicate that women having first and 4th or higher births have higher neonatal, infant and child mortality than birth orders 2 and 3.

\section{(b) Multivariate Analysis}

Although bivariate analysis of the data has demonstrated certain relationship neonatal, infant and child mortality and various socio-economic, biological and environmental factors, we have further sought the net effect of selected variables on the dependent variable in a multivariate context. A dichotomous dependent variable, child's survival status through a specific age range, was defined (child died $=1$; child alive $=0$ ). A number of socio-economic and demographic variables are considered for specific age ranges for multivariate analysis and explained, which are statistically significant.

\section{Neonatal Mortality}

The variables selected in the equation of neonatal mortality pertain largely to biological and prenatal care factors which are proximate to the survival of newly born babies. The results in Table 2 shows that having preceding birth interval of 18 to 35 months lowers the risk of death by 0.72 times the risk of the reference category (less than 18 months), while children having birth interval of 36+ months are 0.56 times less likely to die. Children born to mothers with primary/middle and secondary/ higher have a lower risk of death 0.77 and 0.46 times than the reference category (no education). Having a dead preceding birth increases the risk of dying by 1.80 times compared with having a preceding surviving birth. Also children who are not breastfed had 2.12 times higher risk of dying than those were breastfed. Children of those mothers who had not gone to modern health facilities for antenatal care had 1.51 times higher risk of death than the reference category. Children of

mother's who did not have a tetanus injection in pregnancy were 2.03 times more likely to die than the reference category (tetanus injection in pregnancy). 
Table 2

Logistic Regression Coefficients of the Effect of Selected Predictor Variables on Child Survival: Pakistan, 1990-91 PDHS

\begin{tabular}{|c|c|c|c|}
\hline Variables & Neonatal & Infant & Child \\
\hline \multicolumn{4}{|l|}{ Birth Interval } \\
\hline Less than 18 months & 0.0000 & 0.0000 & - \\
\hline $18-35$ & $-0.3294 * * *$ & $-0.4566^{*}$ & - \\
\hline $36+$ & $-0.5726 * *$ & $-0.8096 * *$ & - \\
\hline \multicolumn{4}{|l|}{ Birth Order } \\
\hline 1 & - & 0.0000 & - \\
\hline $2-3$ & - & $0.4854 * *$ & - \\
\hline $4+$ & - & $0.8795^{* *}$ & - \\
\hline \multicolumn{4}{|l|}{ Immunisation } \\
\hline No & - & 0.0000 & 0.0000 \\
\hline Incomplete & - & $-0.2543^{*}$ & -0.04946 \\
\hline Complete & - & $-0.4479 * *$ & $-0.2965^{* * *}$ \\
\hline \multicolumn{4}{|l|}{ Age of Mother at Birth } \\
\hline $15-19$ & - & 0.0000 & - \\
\hline $20-29$ & - & $-0.3239 * *$ & - \\
\hline $30-49$ & - & $-0.6036^{* *}$ & - \\
\hline \multicolumn{4}{|l|}{$\begin{array}{l}\text { Survival of Preceding } \\
\text { Birth }\end{array}$} \\
\hline Alive & 0.0000 & 0.0000 & 0.0000 \\
\hline Dead & $0.5902 * *$ & $0.4563^{* *}$ & $0.6002 * *$ \\
\hline \multicolumn{4}{|l|}{ Ever Breastfed } \\
\hline Yes & 0.0000 & 0.0000 & 0.0000 \\
\hline No & $0.7512^{* *}$ & $0.4086^{* *}$ & $0.5877^{* *} *$ \\
\hline
\end{tabular}


Table 2-(Continued)

\section{Sex of Child}

Male

$-$

0.0000

0.0000

Female

$-$

$-0.1069$

0.3137*

\section{Antenatal Care}

$\begin{array}{llll}\text { Doctor/LHV/Nurse } & 0.0000 & 0.0000 & 0.0000 \\ \text { Traditional } & 0.4115^{* *} & 0.1997^{* * *} & 0.4201^{* * *}\end{array}$

Education of Mother

$\begin{array}{llll}\text { No Education } & 0.0000 & 0.0000 & 0.0000 \\ \text { Primary/Middle } & -0.2559 * * * & -0.2262^{* * *} & -0.8137 * * \\ \text { Secondary/Higher } & -0.7740 & -0.8458^{* *} & -1.9270^{* *}\end{array}$

Type of Toilet Facility

Flush

Others

$$
0.0000
$$

$0.2123^{* * *}$

0.0000

0.07827

\section{Place of Residence}

Urban
Rural
Tetanus Injection in
Pregnancy

\begin{tabular}{lccc} 
Yes & 0.0000 & - & - \\
No & $0.7083^{* *}$ & - & - \\
\hline Constant & $-3.413^{* *}$ & $-2.077^{* *}$ & -4.147 \\
Chi-square & 105.1 & 158.9 & 54.00 \\
Degrees of Freedom & 10 & 15 & 8 \\
\hline $\mathrm{N}$ & 6923 & 6923 & 6923 \\
\hline
\end{tabular}

Source: Primary analysis of PDHS 1990-91 data set.

* Significant at level $<0.05$.

$* *$ Significant at level $<0.01$.

*** Significant at level $<0.001$. 


\section{Infant Mortality}

The equation for infant mortality includes variables of immunisation, birth order and mothers age at birth to see their impact on an infant's survival. The results show that having a dead preceding birth increases the risk of death by 1.58 times compared with the reference category (alive). Children whose mother's age is 20-29 years are 0.72 times less likely to die than the reference category (15-19 years). Children with mothers aged 30 and above have only 0.55 the risk of dying of those with mothers aged 15-19 years. Children not breast fed are 1.50 times more likely to die than those who are breast fed. The results for birth interval are similar to those for neonatal mortality i.e. longer the length of birth interval the higher the chances of surviving for the infant. Children whose mothers are living in rural areas are 1.41 times more likely to die than those in urban areas. Children given incomplete and complete immunisation have a lower risk of death of 0.77 and 0.64 that of the reference category (no immunisation).

\section{Child Mortality}

The variables birth interval, birth order, birth cohort and place of residence were not found significant with respect to child mortality. Therefore, these were dropped from the final model. In the final model, the significant variables were immunisation, survival of preceding birth, ever breast fed, sex of child, antenatal care and education of mother. Table 2 shows that having a dead preceding birth increases the risk of death by 1.82 times compared with the reference category (alive). Children not breastfed were 1.80 times more likely to die than those who were breastfed. Children given incomplete and complete immunisation lowered the risk of death by 0.95 and 0.74 times the risk of the reference category (no immunisation). Children who had not gone to modern health facilities for antenatal care had 1.52 times higher risk of death than the reference category. The differences in child mortality by the sex of the child show that girls are 1.37 times more likely to die than boys. This implies that son preference and discriminating feeding and child rearing practices in Pakistan may be an explanation for this difference. But the question needs to be investigated further by more specific information on nutrition and food allocation at the household level. Children of mothers with secondary/higher education were 0.15 times less likely to die than children of uneducated mothers (reference category).

\section{CONCLUSION AND DISCUSSION}

The highest mortality occurred among children born to mothers aged less than 20 years. The survival status of the preceding child has a strong association with neonatal, infant and child mortality in Pakistan. The death of a preceding child probably indicates the importance of biological factors, including physiological 
deficiencies in the mother and environmental problems which could carry over to later births. Neonatal and infant mortality is higher for males than for females, as expected; this relationship is then reversed for child mortality. This shows that there are some gender related differences in child rearing practices that favour boys over girls. The analysis of birth order pattern has found mortality to be the highest among first order births, and lowest for third order births before increasing again as the birth order increases. The high mortality of first and high order births may be related to the age of the mother at the child's birth which are termed as high risk births for very young and older mothers. Neonatal, infant and child mortality are highest for children born less than 18 months after the previous birth. The mortality risk then declines as the birth interval increases. These results are consistent with findings from other studies [Gwatkin (1980); Hobcraft et al. (1984); Martin et al. (1983); D'Souza and Bhuiya (1982) and Sathar (1985)]. Differences in infant and child mortality have also been observed according to the place of residence at the time of the survey. Mortality is higher in rural areas than in urban areas as expected. This finding might be due to factors including sanitation, water supply, and unequal distribution of health facilities between rural and urban areas of the country. Considering that about 70 percent of the population of Pakistan live in rural areas, improvements in the above areas through health education and appropriate development plans could help to reduce the level of neonatal, infant and child mortality in rural areas. This may in turn reduce the overall infant and child mortality. Among the socio-economic indicators, the education of mothers who have completed at least primary appears to be the most powerful variable in reducing neonatal, infant and child mortality.

The important conclusion from this analysis of differentials in infant and child mortality is that mother's education, age at birth and birth interval are strongly correlated with lower neonatal and infant mortality. The analysis also suggests that socio-economic factors, in particular education of mother, do contribute to the reduction in infant and child mortality by promoting preventive measures. The higher the utilisation of health services by mothers during pregnancy and after delivery of the child, the lower the infant and child mortality. Therefore, it is suggested that for the improvement of the health conditions of children in Pakistan, first, it is necessary that the educational status of the population in general, and of mothers in particular, should be improved, and second, the health services should be accessible and available for the promotion of health care practices.

\section{REFERENCES}

Afzal, M., T. A. Raja and A. Muhammad (1988) Some Differentials in Infant and Child Mortality Risks in Pakistan 1962-1986. The Pakistan Development Review 27:2 635-642. 
Ahmed, Tauseef, and Mansoor-ul-Hassan Bhatti (1991) Infant and Child Mortality. Chapter in Pakistan Demographer Health Survey 111-123.

Alam, A., and J. Cleland (1988) Infant and Child Mortality: Trends and Determinants. In Iqbal Alam and Betzy Dinesen (ed.) Fertility in Pakistan: A Review of Findings from the Pakistan Fertility Survey. Voorburge: International Statistical Institute 187-212.

Caldwell, J. C., P. H. Reddy and P. Caldwell (1983) The Social Component of Mortality Decline: An Investigation is South India Employing Alternative Methodologies. Population Studies 37:2 185-205.

Caldwell, J. (1979) Education as a Factor in Mortality Decline: An Examination of Nigerian Data. Population Studies 33:2 395-413.

D’Souza, S., and A. Bhuiya (1982) Socio-economic Mortality Differentials in the Rural Areas of Bangladesh. The Pakistan Development Review 8:4.

Gwatkin, Davidson (1980) Indications of Change in Developing Countries Mortality Trends: The End of an Era? Population and Development Review 6:4 615-644.

Hobcraft, J. N., J. W. McDonald, and S. O. Rutstein (1984) Socio-economic Factors in Infant and Child Mortality: Across-national Comparison. Population Studies 38:2 193-223.

Khan, Zubeda (1991) Are Breastfeeding Pattern in Pakistan Changing. The Pakistan Development Review 30:3 297-311.

Martin, L. G., J. Trussell, F. R. Salvail, and N. M. Shah (1983) Covariates of Child Mortality in Philippines, Indonesia, and Pakistan: An Analysis Based on Hazard Model. Population Studies 37:4 417-432.

NIPS (1992) Pakistan Demographic and Health Survey 1990/91, IRD/Macro International Inc. Columbia, Maryland, USA. National Institute of Population Studies.

Rutstein, S. O. (1983) Infant and Child Mortality: Levels, Trends and Demographic Differentials. WFS Comparative Studies 24. Voorburg, Netherlands: International Statistical Institute.

Sathar, A. Zeba (1987) Seeking Explanations for High Levels of Infant Mortality in Pakistan. The Pakistan Development Review 26:1 55-70.

Sathar, Z. A. (1985) Infant and Child Mortality in Pakistan, Some Trends and Differentials. Journal of Biosocial Science 17:3 351-359.

United Nations (1958) Multilingual Demographic Dictionary, English Section. New York: Department of Economic and Social Affairs. Population Studies 29. 